Article

\title{
De-Creation in Japanese Painting: Materialization of Thoroughly Passive Attitude
}

\author{
Kyoko Nakamura ${ }^{1,2,3,4}$ (D) \\ 1 College of Creative Studies, Niigata University, Ikarashi 2-8050, Nishi-ku, Niigata-shi, \\ Niigata 950-2181, Japan; kyoko608@gmail.com \\ 2 Research Institute for Language and Cultures of Asia and Africa, Tokyo University of Foreign Studies, \\ Asahi-cho 3-11-1, Fuchu-shi, Tokyo 183-8534, Japan \\ 3 Waseda Research Institute for Science and Engineering, Ohkubo 3-4-1, Shinjuku-ku, Tokyo 169-8555, Japan \\ 4 Japanese Painting Artist, Art Space Kimura (ASK), Kimura Bld. 2F/B1F, Kyobashi 3-6-5, Chuo-ku, \\ Tokyo 104-0031, Japan
}

check for updates

Citation: Nakamura, K. De-Creation in Japanese Painting: Materialization of Thoroughly Passive Attitude.

Philosophies 2021, 6, 35.

https://doi.org/10.3390/

philosophies6020035

Academic Editor: Timothy Barker

Received: 3 February 2021

Accepted: 8 April 2021

Published: 19 April 2021

Publisher's Note: MDPI stays neutral with regard to jurisdictional claims in published maps and institutional affiliations.

Copyright: (C) 2021 by the author. Licensee MDPI, Basel, Switzerland. This article is an open access article distributed under the terms and conditions of the Creative Commons Attribution (CC BY) license (https:// creativecommons.org/licenses/by/ $4.0 /)$.

\begin{abstract}
This paper demonstrates the method and meaning behind the argument that contemporary philosophers have found the key to "de-creation" in potentiality by implementing it in artwork. While creation in the usual sense seems to imply an active attitude, de-creation implies a passive attitude of simply waiting for something from the outside by constructing a mechanism to set up the gap to which something outside comes. The methods of de-creation are typically found in representations of reality using "Kakiwari," which is commonly observed in Japanese art. Kakiwari was originally a stage background and has no reverse side; that is, there is no other side to the space. Mountains in distant views are frequently painted like a flat board as if they were Kakiwari. It shows the outside that is imperceptible, deviating from the perspective of vision. The audience can wait for the outside without doing anything ("prefer not to do") in front of Kakiwari. It is the potentiality of art and it realizes de-creation. This paper extends the concept of de-creation by presenting concrete images and methods used in the author's own works that utilized Kakiwari. This orients to the philosophy of the creative act by the artist herself.
\end{abstract}

Keywords: de-creation; outside; Japanese painting; art coefficient; becoming; passive attitude

\section{Introduction}

The issues related to art and creativity in this paper are brought in my research with my coresearcher Gunji. Therefore, I will start with the discussion about natural-born intelligence (NBI) and artificial intelligence (AI) proposed by Gunji.

As illustrated by Danto [1], the issue of what art is is immediately relevant for Marcel Duchamp's idea of the art coefficient as proposed in Creative Act [2]. Duchamp proposed artwork as a process of creating rather than something that is created. In other words, after Duchamp, art was shifted from being to becoming. There is a parallelism among art, science and philosophy in the modern era. The idea of becoming is implemented by a dissipative structure in science [3] and is implemented by the philosophy of deconstruction or differentiation [4-7]. Notwithstanding these proposals, the idea of becoming disappears because of the development of globalism based on machine learning, so-called artificial intelligence (AI) thinking. In AI thinking, the universe is just a collection of data. Any object or phenomenon, including AI itself, exists in the universe as a being. The premise of this paper is not an AI thinking worldview.

Does Danto refer to becoming rather than being when thinking about art [1]? He says that art is an incarnation or a real-time dream. Since it sounds as if something outside of the material world can result in materialized artwork, it is too hard to determine whether he is referring to "has become (i.e., being)" or to "becoming". Confronting the globalism of AI thinking has recently resulted in a new realism [8,9] and/or speculative realism $[10,11]$ 
in philosophy. These new philosophies criticize the idea of a uniform world in which everything exists as a being. While they could be strongly related to the new philosophy of becoming, it is hard to see a relation between these philosophies and "art as becoming".

There is one possible connection between these philosophies and art. Gunji proposed the idea of natural-born intelligence (NBI), inspired by Duchamp, and contrasted NBI and $\mathrm{AI}$ in philosophy and science [12,13]. While AI is compared to being, NBI is compared to becoming. At the same time, Gunji and I both turn back to the issue of art as becoming by illustrating my artwork [14]. In my sense, NBI is intelligence that can create something and can feel art. Although both NBI and AI confront the outside of their own perceived world, only NBI can face the true outside [12,13]. If a self-sufficient system works well, the outside of the system is not perceived. In AI, the outside is perceived through the malfunction of the system as what is missing. That is why the outside is always resolved and converges into the system itself as long as the system is sustained. This implies that AI sees only what will be utilized and never sees what is independent of the system itself. In this sense, AI is so active that any phenomenon is reified, operated and utilized. In other words, being is implemented by an active entity.

In contrast, NBI is passive toward the outside. In NBI, becoming is expressed as receiving something outside of the system. In this sense, becoming is not achieved even if becoming is the goal of the system itself. Becoming does not result from active will. Becoming is naturally achieved only by waiting for becoming. Becoming is implemented by passive entities [12-14]. Gunji and I reinterpret the art coefficient as the gap between intent and realization [14], which is the core of NBI. The art coefficient is regarded as the device used to summon something from outside of the perceived world. The meaning of the art coefficient in this paper extends what was taught by Duchamp. I will redefine the meaning of the art coefficient in this paper in the next section.

This thoroughly passive attitude is also referred to by Agamben [15]. The content of a written text is summoned to the blank paper, revealing the absence of the rationale of writing. A piece of blank paper can wait for something to be written. This implies that writing results from a passive attitude and suggests that the absence of the rationale may be a device to summon the outside. Agamben evokes the contrast between creation and de-creation with respect to the context of art. In the context of creation, an artist expresses what is hidden in his/her mind. This implies that the essence of art is hidden inside. By contrast, in the context of de-creation, an artist creates artwork as a device through which something outside of the perceived world can be summoned. Agamben describes decreation as a skeleton in which there is no essence of art. Therefore, de-creation is consistent with NBI, the art coefficient, and a thoroughly passive attitude. While de-creation is a hopeful candidate for bridging art and philosophy with respect to the idea of becoming, the argument regarding de-creation is not clear. When one focuses on the parallelism of the idea of "becoming" in science, philosophy, and art, art can be a theme in which the problem is clarified most clearly. Because creativity plays an essential role in art, creating something that is nothing but "becoming" can be manifested in the context of art. That is why I spell out here what de-creation is in the context of art. That is the implementation of the art coefficient.

In considering de-creation in artwork, I focus here on my own artwork. Considering one's own artwork is both a universal and individual process. It is very important to distinguish the "specific-general" axis from the "individual-universal" axis. If "this" and "that" can be compared with each other, they can be interpreted in a homogenized logical space, which implies that "specific this" and "specific that" can be generalized. Since resolving specificity entails generality, specificity cannot coexist with generality. By contrast, since creating is nothing but creating what did not previously exist, individual creating is not comparable to any other individual things or acts. Creating is singular, and creating carries universal properties since any creation is singular. Although creating cannot be generalized, it is universal. The universal and the individual can coexist. In this sense, the consideration of art is done from a perspective based not on the specific- 
general axis but on the individual-universal axis. If one compares various artworks in a homogenized logical space and abstracts some common property, one is destined to approach this from a perspective based on the specific-general axis. If one focuses on some trends or esthetic attributes in art, no problem arises. However, if one focuses on creativity itself or on what art is, one should refrain from using a specific-general axis. One of the most fruitful ways to argue creativity based on individual universal axes is thinking about an artist's own artwork. The artist's consideration of his/her own work means that the decoding and exploration of creativity are dualized into an individual act of creation. It is a way of demonstrating the individuality and universality that are characteristic of creativity without generalizing the meaning of creation. In this sense, the research style proposed in this paper is similar to participant studies in which patients study themselves in therapy [16-18]. While this method is effective in psychiatry, I think it is also effective in thinking about creativity.

De-creation is implemented as Kakiwari in my artwork. In classic Japanese paintings from approximately 200-300 years ago, distant mountains are expressed like the backdrops painted on boards seen in performing arts. The difference between close and far mountains is ignored, and the ranges are expressed as a flat plane. I call such mountains a flat plane Kakiwari and refer to the art coefficient as Kakiwari. Manifesting how Kakiwari is used in Japanese paintings helps clarify what art is and what an act of creation is. My paper is organized in the following manner. First, I provide the definitions of the de-creation and the art coefficient and describe how they are implemented in NBI. Second, I show what Kakiwari is and what the relation between Kakiwari and the art coefficient is. Third, I show the significance of Kakiwari by referring to my own artwork. Finally, I discuss the possibility of the philosophy of becoming, as demonstrated by Kakiwari.

\section{Potentiality of the Art Coefficient}

First, I convey the original definition of de-creation proposed by Agamben. Agamben [15] draws on a passage from Aristotle to explain potentiality as follows. According to Aristotle, a state of "actuality" in which nothing is written on a blackboard simultaneously implies the state of potentiality in which there is writing on the blackboard. Thus, potentiality refers to the fact that it is possible to prefer to do nothing. Otherwise, potentiality would always be indistinguishable from actuality. Agamben describes this mode of "prefer not" as de-creation [15]. De-creation, that is, the manner in which one prefers to do nothing is the essence of a creative act. In this sense, something expressed is far from art, while expressing nothing entails art since it leads to the potentiality for the audience. De-creation has been cultivated in art since ancient times, especially in the aesthetics of Japanese art.

Gunji explains that potentiality is the ability of a latent thing to manifest [19]. Behind the manifestations of seemingly patterned realizations lies an invisible, uncalculated potentiality. Particularly in the science of consciousness, potentiality is thought to be the breadth and flexibility of the response in realizing a robust and creative reality. Gunji demonstrated this in the mechanism through which humans realize reality. Gunji explains that the reality of the realization that the cat in front of us is a cat comes down to the gap between humans' perception and sensation of the cat, by acknowledging both that it is a cat and that it is not a cat $[13,20]$. In comparing and determining the correspondence between the definition of cats in general and the cat in front of us, the judgmental process of artificial intelligence is strictly looking for the attribute of cat/not-cat and searching for an infinite number of attributes. However, when exercising our judgment in real life, we almost always meet the definition of a cat, "it is a cat," while hiding the obscure details of "it is not a cat" that deviate from the definition of a cat. Thus, we make it possible to make judgments by rounding up attributions at a convenient point in time when judgments are made. In other words, we are in a state of simultaneous realization of the affirmation (it is a cat) and denial (it is not a cat) of a judgment. The cat in front of us, which we realize is a cat, is truly a cat, but it also has many latent possibilities of not being a cat [13,20], and these could manifest themselves at any time. In this way, we are always in a state where the outside is latent. 
We realize a different reality each time we prefer not to make a strict judgment. In other words, it is the constant summoning of the latent outside that makes creativity possible. This is potentiality hidden in de-creation.

In previous collaborative research, Gunji and I found a way to summon the outside in the art coefficient $[12,14,20,21]$ by extending the idea of the art coefficient described by Duchamp [2]. The art coefficient is described as the gap between what the artist intended and what was actually realized in the process of the creative act [2]. Regardless of how much the artist intends to express through his/her work, the result is that the realized work departs from his/her original intention. Further, as soon as the work is appreciated by the audience, the judgment of the work is left to the audience. Therefore, the art coefficient has previously been understood as a gap that is realized by the audience's interpretation, which is independent of the artist's intention. The audience's viewing itself becomes art [1]. Duchamp also explained the process of creating an artwork similarly [2]. On the other hand, Gunji and I presented a new understanding of the art coefficient by suggesting that the work itself is recognized at the point in which it bears the gap between intention and realization, and that an unexpected outside is summoned by the gap $[14,22]$. Gunji and I compared the device making a gap to the entanglement in quantum mechanics and provided it as a concrete image of the art coefficient. This extends the concept of entanglement [14,22]. To implant the art coefficient, it is necessary to construct an exquisite collocation in which intention and realization (disconnection and connection) are realized simultaneously. In other words, it is necessary to construct entanglement. This is demonstrated in the potentiality aspect of the science of consciousness.

On the other hand, it should be noted that potentiality or the outside can be confused with the negation of the inside or chaos to the order. The concept of potentiality examined in this paper is distinctly different from these concepts. The aspect of negation is shown in Magritte's work, which constitutes negation. The words "Cece n'est pas une pipe," which translated to English is "This Is Not a Pipe,"are shown in Magritte's work titled "The Treachery of Images" (1929), where intention and realization are linked in a negative relationship [23]. Negation is thereby repeated recursively. This is the kind of system we see in autopoiesis in systems theory $[24,25]$. The recursive that constantly incorporates the outside to nullify the distinction between the inside and the outside through negation is a closed world that internalizes the outside and repeats the alternation of the inside and the outside.

An arguable outside that can be internalized can no longer be the outside's latent forces (potentialities) that bring about creativity. In the negation that becomes such a notional pseudo-outside, it has no consideration for the outside of repetition. The same characteristic can be ascribed to chaos. Even if the outside is objectified as infinite chaos, it makes the outside possible by manifesting it as a pseudo-outside. Further, chaos does not refer to the outside in the true sense of the word. The larger the gap is, the stronger the power of the art coefficient is in summoning the outside. Nevertheless, simply setting up chaos is just confusion, which means abandoning the art coefficient and the outside. The gap cannot be established by simply introducing easy fluctuations into the creative act. In this sense, Man Ray's photographic composition (1933) of a sewing machine and an umbrella on a dissection table [26] fails to reproduce the dépaysement of Lautréamont's poem: "as beautiful as the chance encounter of a sewing machine and an umbrella on an operating table" [27]. It would be chaos to simply assert that it is a coincidence that these two exclusive objects would meet on an unrelated stage.

On the other hand, in Duchamp's "Fontaine" (1917) [28], the fountain and urinal nullify the exclusive relationship by deviating from the concept of art. The fountain and the urinal, whose relationship has become disjointed, are decolorized in their meanings and contexts and that make it into an artwork by bringing the gap to the blank void [14,21,22]. In this way, the outside can stand behind art, while the latter can have potentiality. This is neither denial nor chaos. The challenge is identifying how the art coefficient can be worked upon to demonstrate its potentiality in summoning the outside. 
The creative act is often thought to be the act of defining the essence of a work of art or life and implementing what we have defined inside the work. However, in this paper, such active creation is not considered creation. In this paper, creation means focusing only on the gap between intention and realization and being oriented around the gap. Creation, in this paper, means a passive attitude of merely waiting for an external visit by constructing a mechanism to create a gap. By considering the passive attitude as de-creation, the original argument about de-creation can be developed in this paper. Gunji and I found that one of the concrete methods of de-creation is the realistic representation that can be called as Kakiwari that is originally just a word implying painted board in Japanese [14,29,30]. As mentioned in the introduction, for a long time, distant mountains have been drawn in Japanese art as if they constitute one flat plane. In aesthetics, there is no description of the mode that uses one flat plane. Flat plane mountains are regarded as a specific design in classical Japanese paintings and are not called Kakiwari in aesthetics.

In contrast, we refer to that specific, significant content by the term Kakiwari. Although this painted board method is used to depict only distant mountains and there is no reference to the outside behind the painted board, Gunji and I reinterpret the flat plane mountain as the device by which something outside our cognitive world can be summoned, and use the term Kakiwari to refer to this aspect (Gunji first called the flat plane mountain in Japanese art Kakiwari in our dialogue in [14].). Although Kakiwari implies the dead end of the perceived world, it does not imply the dead end of a world that cannot be perceived but could exist. In other words, Kakiwari suggests a world outside of our perceived world. Although a flat plane on the stage shows only the dead end of the world, Kakiwari suggests that there is an outside behind it rather than that it is a dead end. In this sense, Kakiwari is nothing but the gap between intention and realization in the art coefficient and nothing but the vacant place in de-creation - that is, the device by which something outside of the perceived world can be summoned. This paper expands the concept of de-creation by presenting concrete images and methods of de-creation through a practical study of art production that expresses and implements the perspective of de-creation.

\section{De-Creation in Japanese Art: The Technique of the Realistic Representation}

Perspective is a method developed during the Renaissance of understanding the world by setting a vanishing point on the horizon of the two-dimensional plane space of a painting to create a three-dimensional perspective. The fact that this can be reproduced on the picture plane is probably the most commonly understood reality at present. In perspective images, however, the outside has been perceived in an exclusive relationship. This is because the moment perspective connects the outside (as an infinite entity) to the space (as a vanishing point), and the outside is materialized as "a vanishing point." In this case, the field of view becomes everything in the world, because it is possible to draw the outside as a vanishing point on the painting plane, which is this side. The process of looking around at the apparent converging pseudo-outside, which is the vanishing point, and of understanding and declaring that this is the world, may lead to missing the real outside. It can be described as a bird's-eye view of the world, a global perspective that surveys the world. Because it is based on a global perspective, which is a prerequisite, everyone can share that worldview in a homogeneous way. However, perspective yields an understanding of the world as a small, virtual space in the envisaged range. As long as we have a view of the perspective of the world, we have to discard the real and the outside. Panofsky noted that the "discovery of the vanishing point as the image of an infinitely distant point is a concrete symbol of the discovery of the infinite itself." On the other hand, he also purported that it discards reality and is "diametrically opposed" to the spirit of reality [31]. Perspective is a rational, realistic technology that allows anyone to easily see and share the virtual world. Such rationality and homogeneity of understanding of the world would have contributed to the development of today's science and logic. However, on the other hand, we have lost this sense because our view has become too accustomed to the pseudo-outside. We can empirically believe that beyond the walls of this room, another 
room exists in the same way. That is a safe world. The "outside" brought about by the perspective is the other side in this simple sense. There is no longer any need to fear that we might encounter an unexpected world (i.e., the real outside) if we turn this bend in the road. Have we not lost the ability to question the closed world of the imaginable and secure?

According to Panofsky, there are no ancient paintings that depict a unified vanishing point [31]. As for Japanese art, perspective was finally practiced to some extent in the middle of the 18th century, but it still did not take hold until the beginning of the modern era [32]. Instead, there are many pictorial expressions in Japanese art that show orientation to the outside.

For example, "rusu moyo" (absent pattern) is a traditional style of painting in Japanese art. Instead of depicting characters from classical literature and anecdotes called "waka" (a Japanese classical poem) and "yōkyoku" (a part of the classical Japanese dance theatre "noh"), the artist uses tools and background designs that symbolize the theme of the character or the story to evoke the scene of the theme. The "Tagasode" (Whose Sleeves?) screen [33], as shown in Figure 1, is one of the subjects depicted on a folding screen (called "biombo" in Europe) that has been drawn since the Edo period (17th century). The clothes hanging on the girder suggest the image of the wearer. As for the title, the word Tagasode suggests that the work is seen as an allusion to its subject by using rusu moyo. However, while it is understood as a symbol of absence, it is not the only symbol. It is said that the formation and development of the Tagasode screen and the purpose of its theme are not clear. The term Tagasode was used in "Kokin Wakash $\bar{u}$ " (a collection of ancient and modern Japanese poems, 10th century) to refer to a type of scented bag. The term Tagasode screen is said to have originated because this term was diverted as the name of its style. It is said that this was after the Meiji period (after the 19th century), and originally, this style of folding screen painting was called "Ikō- $g a$ " (painting of clothes girder) [34]. Some Tagasode screens make extensive use of the technique of production for kimono-style garments rather than hand painting. From this, Okuda hypothesizes that those Tagasode screens were created on the sidelines of the production of kimono-style garments [34]. The viewer is drawn to the beauty of the clothing and the flora and fauna that appear in the patterns, and they let their ideas fly. In this way, the viewer is oriented towards the absence of this context but simultaneously deviates from it. The garment has a context of absence. At the same time, however, the context is decolored by drawing the viewer's attention to the disordered row of garments with excessive and diverse designs, thus separating the viewer from the subject of absence. As the viewer focuses on the planar ornamentation of the disparate garments, the other side, indicated by the clothes girder that separates the space, is not absent. The planes of the Tagasode screen hold the outside behind them. This device of the plane realizing the outside can be captured more explicitly in another characteristic of Japanese art, realism.

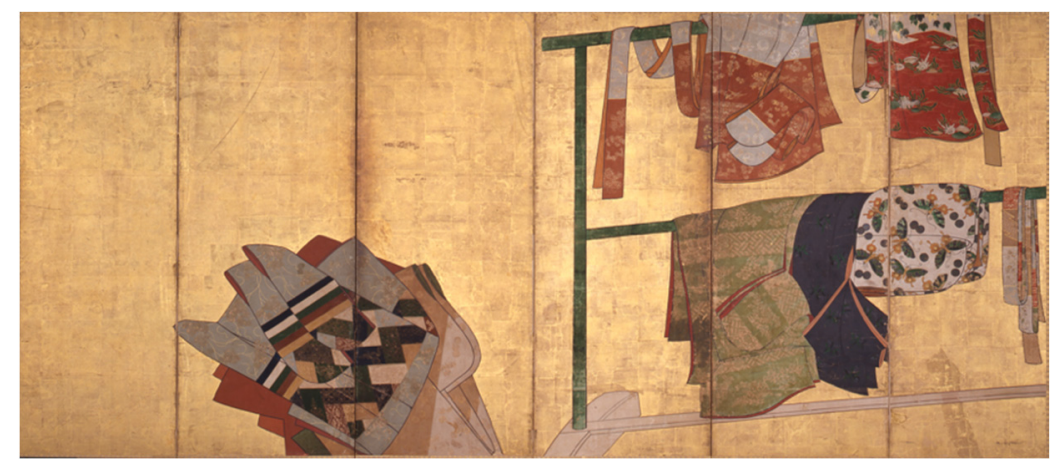

Figure 1. Author unknown, Whose Sleeves? (Tagasode Screen), six-fold screen, color on paper, $149.5 \times 348.2 \mathrm{~cm}, 17 \sim 18 \mathrm{c}$, Mitsui Memorial Museum, Tokyo, Japan. 
Mount Utsu, a mountain in present-day Shizuoka Prefecture, Japan, was the setting for "The Tales of Ise" [35], a poem-tale written in the Heian period (both the year of completion and the author are unknown). "Tsuta no Hoso-michi" (narrow ivy road), an ancient road from the Heian period that remains in the mountain, is a mountain pass that runs through Mount Utsu and connects Kyoto (the center of Japan at the time) with the eastern part of the country. "The Tales of Ise" contains a famous scene in which this road is crossed by the main character during an "Azuma kudari" (a journey eastward from Kyoto). Thus, the painting "Mount Utsu" (1755-69; please visit the museum website [36] to see the painting, because no permission was given to reproduce the photo in an open-access journal) by Yamamoto Tansen depicts a scene of the crossing the mountain pass at Utsu, as described in the story, but it does not depict any characters. Therefore, the painting is said to be in the style of rusu moyo. Rather than the subject of absence, however, our eyes are focused on the series of green semicircles. This method of depicting mountains is said to have been influenced by Ogata Korin, and it is a common way to represent the mountains in "Rimpa," which is one of the major historical schools of Japanese painting [36]. Two-dimensional mountains may be considered childish by a modern audience familiar with realistic imagery that skillfully constructs perspective space. However, viewing this mountain as a papier-mâché painted board plane, like a stage backdrop, which is referred to as Kakiwari in Japanese, can illustrate this study's original argument for the process of enabling the outside [14,29,30].

The series of Kakiwari, board-like mountains that form an abstract yet realistic landscape, show that there is no back side=other side (world) to them. There is no vanishing point in the realism of Kakiwari. The series of Kakiwari, board-like mountains that form an abstract yet realistic landscape, show that there is no back side=other side (world) beyond them. There is no vanishing point in the realism of Kakiwari. They present only the reality of this side. Our view of the world through Kakiwari does not make visual farness or nearness an issue. Kakiwari deviates from the spatial concept of perspective by having no reverse side. Kakiwari cuts off infinity using the finite. Thus, the viewer does not or may prefer not to look at the entirety of the painting space. Kakiwari presents the unseen outside. The other side of the mountain, where the exclusivity of the figure and ground is nullified, is not the other side. The outside lies behind that mountain.

Absence is assumable because it is assumed to be absent. Absence is established by the fact that absence is intended or realized. The gap between the intention and realization of being absent is not required. Therefore, the art coefficient is small. The outside does not lurk in the state of absence. On the other hand, the viewpoint in Kakiwari, which is placed on the reverse side of nothing, does not intend to be absent. Facing Kakiwari, the viewer does not simply let the absence be an absence just as it is, but he/she decolors the context of the absence. This allows us to acknowledge an outside that is present but not perceptible. It is the outside that Kakiwari's viewpoints realize through a tasteful appearance of the outside. It can be said that the ancient tradition of Japanese art aims to challenge the concept of an inaccessible outside. In the face of Kakiwari, we can believe that the outside exists and that we can wait for it to arrive. Rather, all we can do is wait. It is a thoroughly passive attitude of "prefer not to do." This is the technique of de-creation in Kakiwari.

In this way, Kakiwari of which the close view (A) and far view (B) is mixed with up with each other in a flat board implies that neither original meaning of (A) nor (B) defined by distance exits while both (A) and (B) exist in Kakiwari. Although this sounds like confusion, both bridging (A) with (B) and separating (A) from (B) can open the vacant gap between (A) and (B), which entails summoning something from the outside. That is the core of Kakiwari, and generalizing close view and far view to (A) and (B) is the core of NBI. The idea of mixing (A) with (B) is directly connected with NBI, different from AI. In AI, making any concepts (A) and (B) connected to one another with respect to a certain structure is understanding (A) and (B). That implies a creation in simple thinking, a perspective set by a vanishing point. By contrast, in NBI, de-constructing the problem to connecting (A) and (B) is understanding. Thus, it looks de-creation from the perspective of simple thinking; however, it implies true creation. The creative act of waiting, which is the de-creation, is 
possible because of NBI. In this sense, the creative act, including my own practices, is the practice of NBI.

The attitude of de-creation, in which people wait for the outside to come from over the mountain, is also evident in the ancient Japanese view of life, death, and nature. Since the Heian period (10th-12th centuries), the belief in Amida Buddha coming from over the mountain to take us to the Pure Land of Ultimate Bliss (the paradise free of suffering where Amida lives) is widely held [37]. Figure 2a, "Descent of Amida (Amitabha) over the Mountain" [38] is a Japanese painting that illustrates this belief. To ancient people, the other side of the mountain was the unseen outside world. In front of the Kakiwari Mountains, which separate this side from the other side, they waited faithfully for Amida's manifestation. They do not actively try to access the outside. They are active in not being able to access it. However, because the outside is imperceptible to the ancient people, that is where the next world was meant to be. As a result, it should be noted that the other side tended to be understood as a Buddhist worldview rather than as the outside. Figure $2 b$ is Mt. Futakami, a mountain where "Chüjo-hime," Middle Captain Princess (747-775) is said to have had an encounter with Amida Buddha [37]. There are two peaks on the mountain; one of them is Medake, literally "female top" and the other one is Odake, literally "male top." The tomb of Prince Ötsu, the son of Emperor Tenmu, is located on the summit of Odake. This tomb is under the jurisdiction of the Imperial Household Agency. Prince Ôtsu (663-686) appears in the "Nihon Shoki" (Chronicles of Japan, around 8th century), Japan's oldest historical and mythological book.

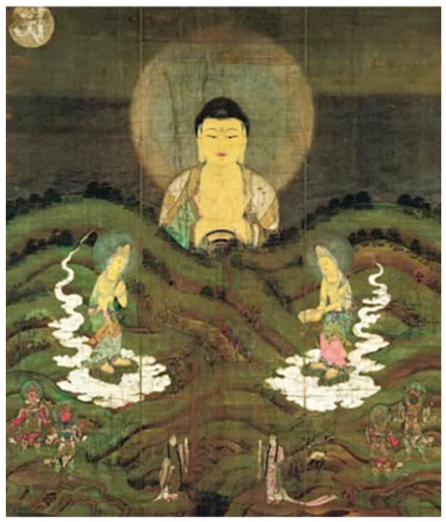

(a)

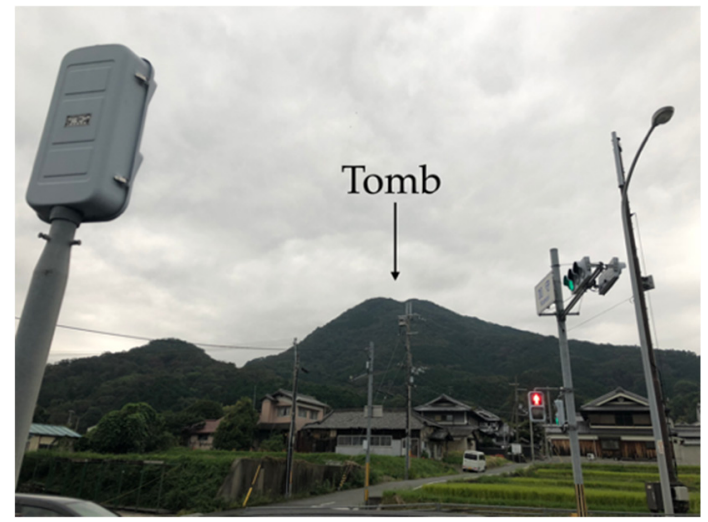

(b)

Figure 2. Images of the Japanese ancient mountains: (a) Author unknown, "Descent of Amida (Amitabha) over the Mountain", hanging scroll, color on silk, $138 \times 118 \mathrm{~cm}, 13 \mathrm{c}$, Eikando Zenrin-ji Temple, Kyoto, Japan; (b) Mt. Futakami (Nijo), right side peak called Odake (literally, "male top").

In the "The Book of the Dead" (1939), which is based on the belief that Amida Buddha arrived from over the mountain, the princess encounters this prince [39]. The tomb at the top can be thought of as a device that summons the outside in the real world. When we actually climb up the mountain, the other side, which we could see earlier, is perceived to be as expansive as this side. Therefore, in the real world, there is no other side of the mountain that we cannot perceive. However, from the base of the mountain, the graves on the summit are a sign of the mountain itself, which suggests the existence of the other side of the mountain. The fact that the mountain itself is a grave suggests that the soul of the buried exists on the other side of the mountain and that the grave is on the other side of the mountain. As we ascend the mountain, the grave (the other side of the mountain) gets closer, but the "other side" does not extend from the summit to the base of the mountain. Rather, it shrinks in size until it finally converges on the summit. This convergence is, in principle, a convergence and disappearance to a point, a deviation of the spatial concept. The other side then becomes the outside. The mountain-top tomb may have been a way for 
ancient people to set up the real Mt. Futakami as a device to make it look like a Kakiwari mountain [14].

\section{Tradition of Creative Act in Japanese Painting: Consideration for the Outside}

Currently, we call paintings using traditional Japanese techniques "Japanese painting" (in Japanese, "Nihon- $g a$ "). Techniques of Japanese painting are said to have been originally brought from the continent between the Nara and Heian periods (around 8th-12th century). These techniques were developed in Japan by following the techniques from the continent. In the study of Japanese art history, paintings are referred to by different names depending on their historical background, such as "Kara-e" or "Yamato-e". Just as oil paintings are called so because of the technique of using oil, there is also an idea of the name for Japanese painting to call "Nikawa-e" because its gelatin ("Nikawa") is a fixative.

The term "Japanese painting" first appeared in the Meiji era (around 19th century), and it was first used by a foreign researcher, Fenollosa, to introduce Japanese art to the West. The researcher was an American who had studied oil painting. It is said that he was devoted to the classical arts inherited from the Greeks and Romans and that he considered such ancient aesthetics to be the foundation of and tradition of art [32]. For Fenollosa, only one artistic tradition existed, and it was neither Eastern nor Western; he felt that this tradition was already being lost in Western art at the time. Fenollosa then discovered the artistic traditions in Japanese art [32]. What did Fenollosa find that was different about Japanese paintings in contrast to modern paintings in the West? Where did he find the "tradition" in Japanese paintings? Another foreign researcher, Hearn, who was deeply devoted to Japanese aesthetics, wrote several books on Japanese culture. In one book, Hearn argued that the aesthetics of Japanese art were "a talent for avoiding any sense of orderliness and regularity, or tendency to do so" [40]. For Hearn, the Western aesthetic was one that had developed by personifying nature as if humans were connecting to a vanishing point. In contrast, the Japanese decorative arts had consideration for the outside, a thoroughgoing departure from a state of overview and control of nature. This must have been the tradition that Fenollosa discovered in Japanese art. It is an idea that is consistent with the concept of de-creation.

The viewpoint in Kakiwari is a method of de-creation that dexterously avoids being prescribed by avoiding any tendency and context to draw a line that passes through the center of vision. In the Kakiwari viewpoint, the artist focuses only on the mechanism for summoning the outside and leaves the space, or the gap, between intention and realization empty. The following examples show the Kakiwari viewpoint. Figure 3a is a Japanese painting by Ito Jakuchū, one of the 30 paintings of the "Doshoku Sai-e" (30 hanging scrolls comprising the work, Colorful Realm of Living Beings) depicting animals and plants. Although some say that the 30 paintings were originally arranged around the three Buddhist paintings included, they are essentially viewed as independent [41]. The 30 paintings lack subject matter and are deployed as disparate Kakiwari-like painting planes, each unrelated to the others. It is, as Hearn pointed out [40], a model that allows humans to take the outside world into consideration without unnecessarily ascribing any meaning to nature. The natural landscapes, flora, and fauna depicted in the paintings do not lose their latent power simply by being composed of nature as it exists. In this way, the disconnected series of 30 disconnected painting planes gives us a consciousness that meets the outside world in reality.

In Figure 3b, a still life of a "Watermelon" by Hokusai [42,43] shows a watermelon cut in half and seems to have something unusual behind it. Some interpreters have attributed this work to the symbol of "Kikkoden" (the star festival), since the theme of the star festival is found in the combination of motifs in this work [44]. However, just like "Mitate- $e^{\text {" }}$ (an expression that means "to liken one thing to another"), in the subgenres of Japanese painting, or "vanitas," still life is intended to be an allegory. Nevertheless, the present manuscript does not aim to provide a predetermined interpretation of the motifs in this work. Rather, in mentioning the star festival, I focus on the universal custom of ancient 
peoples of composing a two-dimensional space by stretching colored threads across threedimensional space. In a direct fact, the picture merely depicts hanging watermelon skins, which, like a curtain, simply separates us from the outside behind us. This still-life painting seems to convey only the subtleties of the outside.

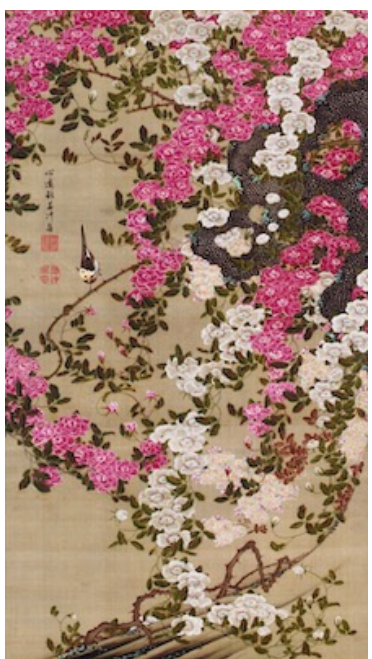

(a)

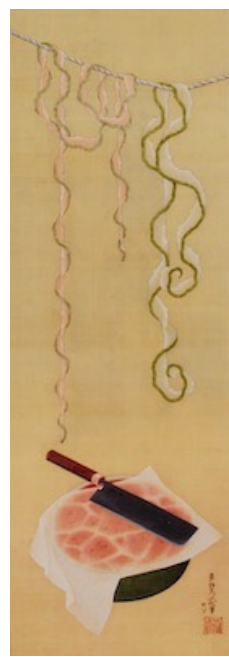

(b)

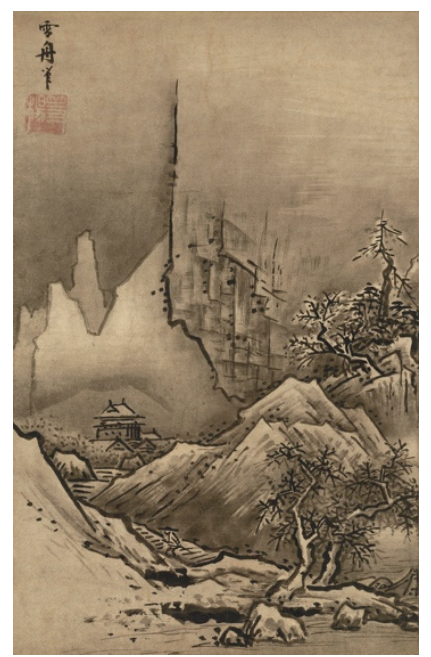

(c)

Figure 3. (a) ITO Jakuchū, "Bara Shōkin-zu" (Roses and Small Bird), one of the painting "Dōshoku Sai$e^{\prime \prime}$, hanging scroll, color on silk, $142.6 \times 79.7 \mathrm{~cm}, 1761-1765$, The Museum of the Imperial Collections, Sannomaru Shozokan, Tokyo, Japan; (b) KATSUSHIKA Hokusai, "Watermelon", hanging scroll, color on silk, $86.1 \times 29.9 \mathrm{~cm}, 1839$, The Museum of the Imperial Collections, Sannomaru Shozokan, Tokyo, Japan; (c) SESSHŪ Tōyō, "Landscapes of Autumn and Winter", hanging scroll, ink on paper, $46.3 \times 29.3 \mathrm{~cm}, 15 \sim 16 \mathrm{c}$, Tokyo National Museum, Tokyo, Japan.

In the landscape painting by Sesshū in Figure 3c [45], a bold, thick line is drawn vertically in the center of the picture. At first glance, it is difficult to understand that it indicates the line of a rocky mountain ridge. This line appears to be independently individuated. It can be seen as a line that, like Kakiwari, nullifies the spatial concept. While showing a realistic space as a ridgeline, the line simultaneously summons the reality of a different dimensional landscape beyond the simple concept of space in terms of perspective. I had the same experience in childhood. When drawing an apple on a table, children often tend to draw a horizontal line on the picture and then draw the apple on it. It is a two-dimensional grasp of space, viewed from a side angle. However, as children grow and begin to understand perspective, the horizontal line emerges above the apple's overhead. That line is also perceived as a marvelous line floating in the air, even though it is understood to be the ridgeline of the table. The deviation of the spatial concept through the coexistence of this ridgeline and the line in the air, and the intense sense of discomfort caused by it, is a gap, which is as the art coefficient. Evidently, these artworks depict reality as what is here now in the present. They do not give us room to objectify the outside in a context that can be interpreted. They do not attempt to represent the outside directly. Rather, they show it to us by giving us a crack in our appreciation of what is depicted, that is, by setting up Kakiwari. This is to say that they show the outside without touching the outside. This is creation as de-creation in the act of art.

\section{Practice 1: Wait for Flower-Holding Birds}

I found a sign of de-creation itself, i.e., waiting, in my own art practice. The concrete practice of de-creation is described below.

The aforementioned "The Tales of Ise" has been a popular subject in Japanese art for a long time. In particular, several artists have painted the scene of "Azuma kudari." I have also used the "Azuma kudari" scene as a subject. It is said that the protagonist in "The Tales 
of Ise" is the poet Ariwara Narihira. "The Tales of Ise" contains many of Narihira's poems, which can be read as a chronicle of Narihira's love life. In "Azuma kudari," Narihira loses his love and leaves his lover in the capital (present-day Kyoto, Japan) and travels to the east in loneliness. This is a story about the journey across the mountain road called "Tsuta no Hoso-michi," which leads from west to east. Tsuta no hoso-michi is dark and narrow, and the ivy is so thick that it makes Narihira feel lonely. Narihira unexpectedly meets the ascetic monk he has met before. He entrusts the monk with a letter he has written to his lover. In the letter, Narihira writes the following famous poem [35].

Suruga naru Utsu no Yamabe no Utsutsu nimo Yume nimo Hito ni Awanu narikeri.

The poem, written in an archaic language, can be translated into modern English as follows:

Not only in the real (Utsutsu) on Mt. Utsu of Suruga but also in dream I cannot meet my lover.

The first phrase of the poem, "Suruga naru Utsu no Yamabe no," means "in the Mt. Utsu of Suruga country (now it is called as Shizuoka, Japan)", as shown below in red. The next word, "Utsutsu" means "real" or "present." The name "Mt. Utsu" comes from the name of the place where this mountain is located, and it is symbolized by the word "Utsutsu," which has a similar sound but a different meaning (the word "Utsutsu" has yet another meaning, but I will address that later). "Yume" means "dream," as shown below in blue, which is the virtual, the other side of the real, or the outside. "Hito" means a person left behind in Kyoto, and "Awanu" means that he cannot meet her. In this way, "Hito ni Awanu narikeri" is a song about loneliness, which refers to Narihira's inability to meet his lover either in the real or in the outside.

Suruga naru Utsu no Yamabe no Utsutsu nimo Yume nimo Hito ni Awanu narikeri.:

Not only in the real on Mt. Utsu of Suruga but also in dream I cannot meet my lover.

I mentioned above that dreams are virtual, but that is actually a simplistic way of thinking about them. People today understand that dreams are virtual or external to the real, they distinguish between these concepts, and they know that the relationship between the real and the outside is distinct. People today do not readily believe that from the outside, with which they have exclusive relations, can come into the real world. However, dreams are not merely virtual. The ancients did not live their dreams as virtual which was an exclusive relationship to reality. It is said that people in the Nara period believed that a person who cared for them would appear in their dreams. Therefore, the fact that Narihira's lover does not appear in his dreams means that she no longer has feelings for him. On the other hand, if we readily adopt this belief of ancient peoples and think that reality and the outside world are correlated, Narihira will truly never see his lover again. Dreams and reality are more than just connected to each other.

In the Kakiwari viewpoint, which evades both correlation and exclusivity, there is still a sign of connection between Narihira and his lover. That is, the mountain of "Utsutsu=Utsu." In the world of the Kakiwari mountains, there is a complete disconnect between this side and the outside. There is nothing we can do in the face of this disconnection, but Kakiwari allows us to do nothing. In other words, being disconnected opens up a passivity that leads us to "wait." By understanding this disconnection, we can simultaneously wait for the outside and trust the outside. This disconnection and connection refer to "meeting." In modern language, "Utsutsu" has another meaning, a state of uncertainty between dreams and reality, literally "Yume-Utsutsu." This is because the word "Utsutsu" is frequently used in the form of "Yume or Utsutsu", which is a meaning that was established inadvertently. Such a coexistence of connection and disconnection and the fact that dreams and reality are not simply exclusive can be read in the word "Utsutsu" in Narihira's poem. The dream and reality are thoroughly disconnected. By being disconnected, they are open. It can be said that "Yume-Utsutsu" is a reality of Kakiwari. An unnamed reviewer of this paper made 
the following point about this reality: dreams may be "virtual," but waking reality may also be. Narihira can dismantle the distinction between the real and the unreal, trust in the arrival of the outside world, and simply wait. There is a consideration for the outside world that lies behind him that allows him to accept loneliness as a wonderful, beautiful thing $[14,30]$. The reviewer said, "Dreaming may be considered a kind of passive creativity in which one is observing oneself-this may have an interesting relationship to 'gaps' and de-creation." I would like to see the function of dreams as a subject in future work.

When I saw "Yume-Utsutsu" as an entanglement of disconnection and connection, the challenge was implementing this in the artwork. In other words, it was a challenge to find a way to summon the outside without painting the outside from this side. This was a practical method for creating a work that implements and presents itself as "waiting."

Before I paid attention to the subject of the mountain, I had the experience of meeting one who could show the "waiting." Once, while I was walking along a path through a rice field, a large heron came out of nowhere with a leaf and a branch in its beak, skimmed over my head, and flew into the nearby forest. The image of a bird coming from somewhere with something in its beak has been related to human beliefs since ancient times. It was a dove that had an olive branch in its beak that heralded the arrival of the new world in the bible; it was the sign of the new world. At a time when there was no way to know the location of a ship on the open sea, a bird flew to humans from the other side of the ocean, which they could not see, obscured by the endless horizon - the opposite of the style of Kakiwari-and brought plants and trees that indicated the existence of a continent beyond our perception, which we thought did not exist. In Japanese art, the image of this bird appears as flower-holding bird patterns, called "Hanakuidori" in Japanese. The patterns of flower-holding birds can include various birds with flowers, ribbons, and beads in their beaks. Such birds crossed between the continents of the East and West and were introduced to Japan via the Silk Road. Its decorative beauty blossomed in Japan from the Asuka period to the Tenpyo period (6th-8th centuries) [46]. Many of the surviving treasures associated with the emperor in the Tenpyo period are decorated with flower-holding birds. Such birds fly around to decorate many objects such as rulers (see Figure 4a) [47], Go (game) stones, desks, and boxes. The flower-holding bird patterns were cherished by ancient peoples as a device for conveying auspicious signs. In other words, flower-holding birds are messengers who bring imperceptible external signs and even show the significance of de-creation, which involves waiting for or the arrival of something.
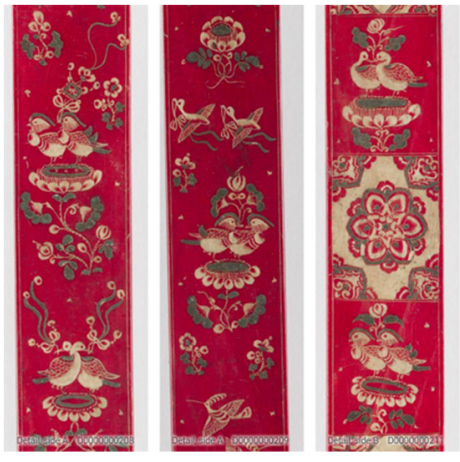

(a)
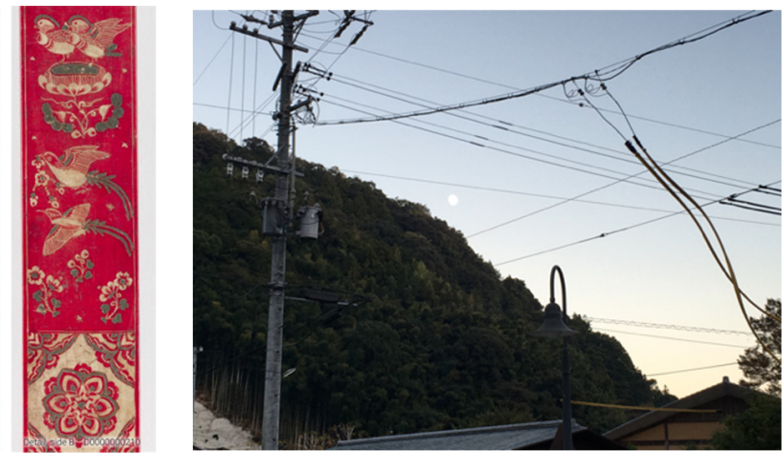

(b)

Figure 4. (a) Author unknown, Shōsōin Treasure: red-stained ivory shaku ruler with bachiru decoration, (乙) (cropped images), detail: side A D0000000208, side A D0000000209, side B D0000000211, side B D0000000210, ivory dyed in red (Bachiru), $29.8 \times 2.6 \times 0.7 \mathrm{~cm}$, Imperial Household Agency, Shōsōin, Nara, Japan; (b) The Mountain breathes out the moons.

Passing through the mountain pass at Utsu, we come to the mountain village of Mariko. The village is surrounded by mountains with a 360-degree field of view. When we walk through the village, because our viewpoint moves, moons appear from everywhere 
behind every ridgeline of the mountains (see Figure $4 \mathrm{~b}$ ). This area has been called "Togepp $\overline{0}$ ", which means a peak that breathes out the moon. Seeing the moon breathes out of the backside of the mountains, I was suddenly reminded of the flower-holding birds that I had seen in the past. In the valley of Utsu, a small, fragile moon bead, like a burial offering, was brought to me by the flower-holding birds (Figure $5 a, b)[14,29,30]$. These were signs of the outside. Thus, our view of the world is not infinite. The landscape (world) is not something that can be viewed indefinitely. Therefore, there is no vanishing point in the world. The view of the world is bounded by Kakiwari at a finite place and is divided into a finite number of segments. We cannot perceive the other side of the Kakiwari, but we can feel the existence of something related to this side of the Kakiwari. Therefore, we can expect to see something coming up from the other side, as signified by flower-holding birds. Mountains, like Kakiwari, are a metaphor for a finite world. The other side and this side are, in this sense, able to coexist in disconnection and connection. This is the de-creation of waiting for flower-holding birds.

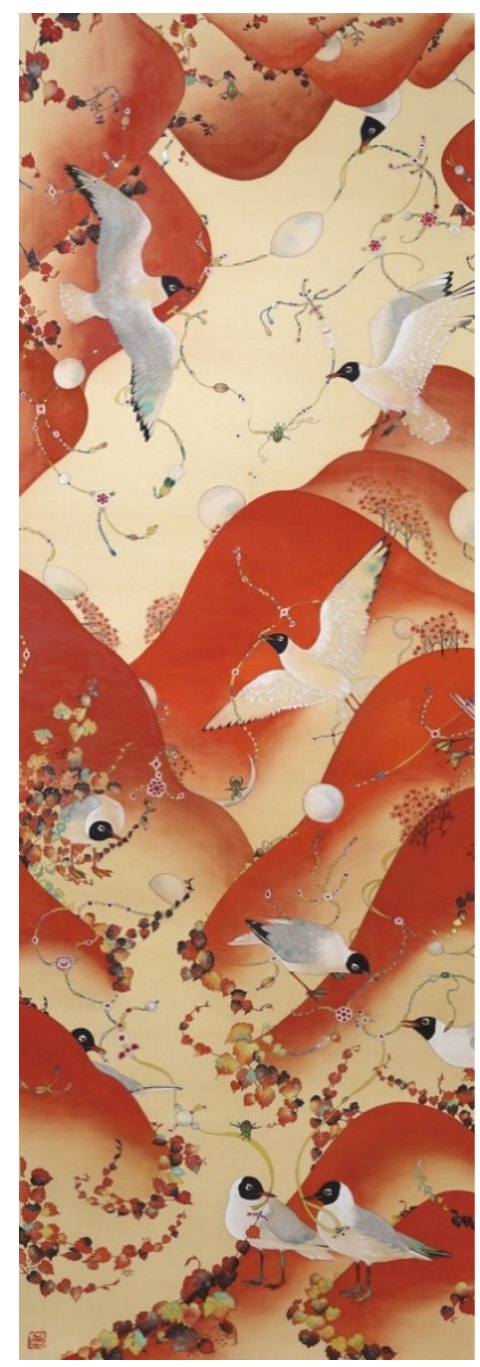

(a)

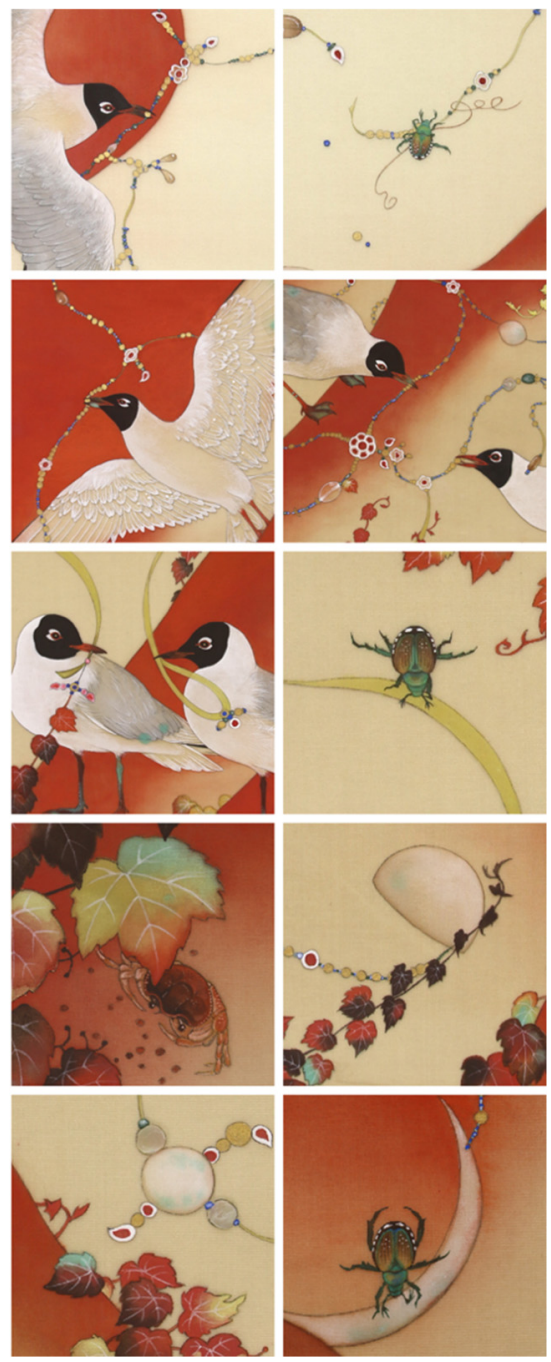

(b)

Figure 5. (a) NAKAMURA Kyoko, "Wait for Flower-Folding Birds", color on silk, hanging scroll, $153 \times 50$ cm, 2018.; (b) Detail of painting. Painting mounted by Sōgadō, Tokyo, Japan.

\section{Practice 2: "Onbashira" as Large Log}

As established earlier, we should not try to express the outside, shape it, say that we saw the outside, or touch the outside impertinently. De-creation is the process of ascribing potentiality to even a single empty log. We focus only on the mechanism in front 
of us, where the outside comes down, and we wait for the rest to appear. In "Onbashira" (Figure 6), in my hometown of Shimosuwa, Nagano Prefecture, I found a model that makes the de-creation of waiting possible.

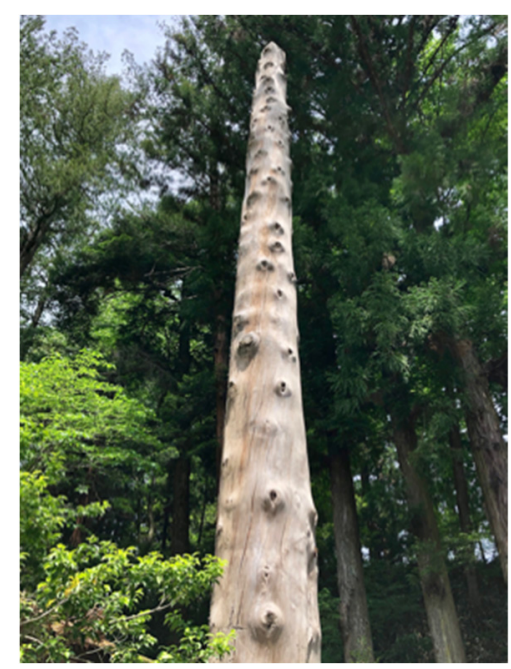

Figure 6. The sacred pillar called as "Harumiya ichi no Onbashira", the thickest of the four pillars built in the Shimosha Harumiya (Lower Shrine Harumiya) of Suwa Taisha in 2016.

Four Suwa Taisha (Suwa Grand Shrines) are located in Suwa. They are the headquarters of all of Japan's Suwa shrines, located around Lake Suwa, with Maemiya and Honmiya being located in the Kamisuwa region and Akimiya and Harumiya being located in the Shimosuwa region. The Onbashira festival is held at each of these shrines once every six years. The Onbashira festival is a ritual in which four large pillars, "Onbashiras," are erected for each of the four corners of the Suwa Taisha shrine $[48,49]$. Figure 7a-g presents pictures of the Onbashira festival in the Shimosuwa area in 2016. The year before the Onbashira festival, the priests of Suwa Taisha visit the Suwa Shrine on the border of Nagano and Niigata prefectures. At that shrine, a mysterious bird-shaped object called "Nagi-gama" is hammered into a large tree at the shrine during a ritual ceremony [49]. The meaning and origin of the Nagi-gama are unknown. It is customary to cut down the large fir trees for the sacred pillars of Suwa Taisha from Mt. Okoya in the city of Chino in the Kamisuwa region and from the national forest of Higashimata in the town of Shimosuwa, Shimosuwa region $[48,49]$.

The selected large trees are marked as sacred by etching Nagi-gama on them or by stretching Shime-nawa, a thick, twisted straw rope with stripes of white paper, across it. In the Shimosuwa area, one year before the festival, the trees are cut down, the bark is stripped off, and they are processed into logs [49]. The Onbashiras are processed in this way and weigh approximately 10 tons, with a diameter of approximately $1 \mathrm{~m}$ and a height of approximately $17 \mathrm{~m}$ [48]. The Onbashira festival is divided into two parts, "Yamadashi" and "Satobiki." Yamadashi is a ritual in which the logs of Onbashira are carried from deep in the mountains to the village of Suwa Taisha. On the day of the festival, the purified Onbashiras are taken from Tanakoba, passing through the mountains (Figure 7a,b). In this ceremony, the townspeople hook each rope to the thick rope tied to the Onbashiras to move it collectively. During the festival, the people pull the rope to the ground, accompanied by "Kiyari" (a traditional Japanese folk song). The Kiyari song echoes throughout the festival. On the way to the festival, people need to descend from a difficult part of the slope of "Ki-otoshi Zaka." We call this ritual "Ki-otoshi," and the heroic Ki-otoshi is one of the highlights of the Onbashira festival (Figure 7c-e). Specially selected riders are allowed to ride astride the Onbashiras. The person in the front row is called "Hananori" and plays an honorary role. They then drop the Onbashiras from the top of the hill of Ki-otoshi Zaka and continue to straddle over them. Sometimes they can stay on the log to the end, sometimes, 
they are shaken off, and sometimes, accidents occur. After descending the mountain, the Onbashiras lays in wait for a while. Then, during "Satobiki," the Onbashiras pass through the city. A spectacular parade of traditional performing arts is also held around Akimiya, Suwa Taisha. After arriving at the shrine building, the Onbashiras are erected vertically after a ritual called "Kanmuri Otoshi," in which the tips of the logs were shaped like a triangular pyramid (Figure 7f,g). Here again, the Onbashiras are erected vertically with selected riders on them. Here again, several accidents such as falls may occur.

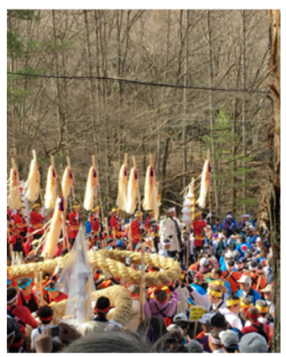

(a)

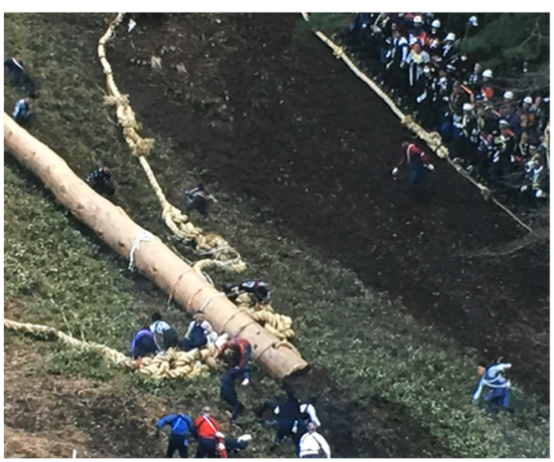

(e)

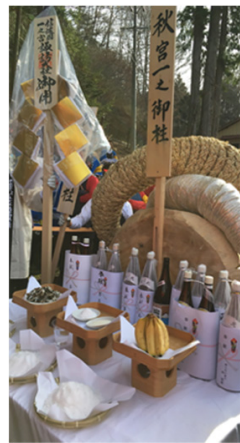

(b)

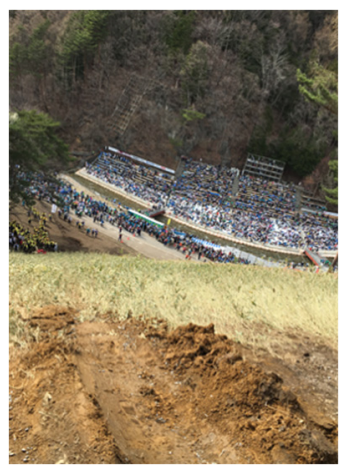

(c)

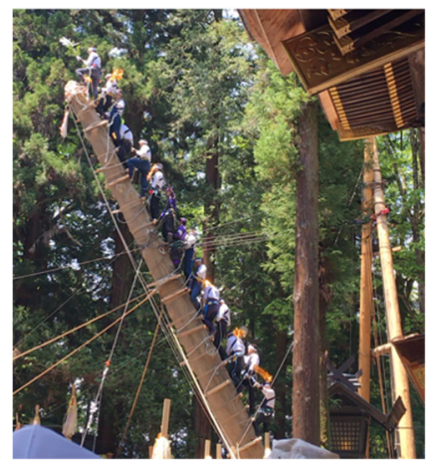

(f)

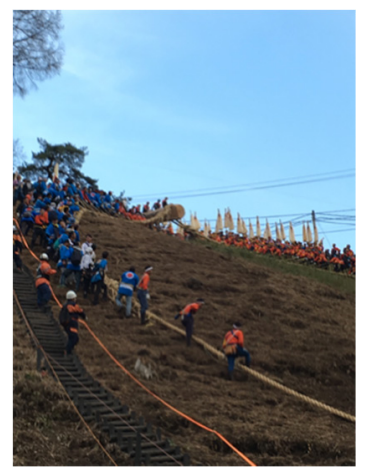

(d)

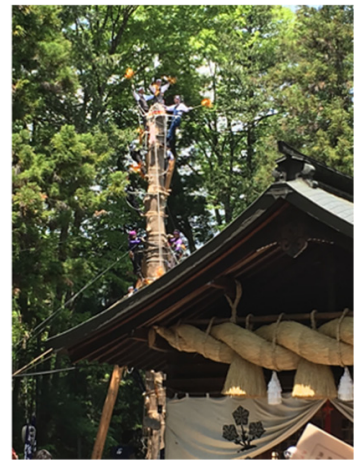

(g)

Figure 7. The Onbashira festival in 2016: (a) Tanakoba, the starting point of the festival of Yamadashi; (b) Onbashira being purified before the beginning of the festival; (c) View from the top of Ki-otoshi Zaka with its 35 degrees slope. The soil on the ground was removed when Onbashiras were dropped; (d) Just before the drop of Onbashira on the slope; (e) Ki-otoshi is the highlight of Yamadashi (this picture is taken from the TV screen of LCV (LCV Corp. is a cable television station serving Suwa and Tatsuno areas in Nagano Prefecture), which broadcasts the scene of the festival in real time, as it is dangerous to take part in Ki-otoshi Zaka); (f) The festival of Satobiki, where the Onbashira was brought to the precinct and gradually erected vertically; (g) The vertical standing Onbashira.

The origins of the Suwa beliefs are so ancient that they are unknown. The native gods of Suwa are even mentioned in some of Japan's earliest myths, but there is not much literature on Suwa beliefs. Therefore, we do not know why the Suwa people erect these sacred pillars or what the sacred pillars represent. Despite not knowing this, we do know exactly what is done during these rituals and how it is done. That is, four large logs cut from the mountain are erected at the four corners of the shrine building. There are various theories about the Onbashira. In the Kamisuwa region, it is believed that the Onbashira is associated with the indigenous god "Mishaguji." According to this theory, there are huge trees, such as cypress trees, growing near a small shrine that houses a stone pole at which a ceremony is performed to invite Mishaguji. These trees, in contrast to the Onbashira, were believed to be rooted deep down into the earth [50]. In other words, the theory is that Mishaguji comes down through living trees, takes root, and connects with the outside world. 
This belief suggests that these trees are prototypes of the Onbashira. Thus, the Onbashira is viewed as a boundary connecting with the outside, an interface mediating the outside.

However, if this is true, the outside is only a pseudo-outside that can be brought to as our side. Consistent with this hypothesis, the outside is something that can be predefined and sealed inside. This is the aspect of the inwardly closed creation that the present study denies. Conceiving of a recursive computation that continues to embody the pseudo-outside still falls into the same problem faced by today's philosophy and science of consciousness, which have not found a way to avoid breaking down in the frame problem (the outside) [51-53]. On the other hand, the main point of interest in the above hypothesis is that the current object used in the Onbashira is seen as just a log. It might be thought of as a processed good that has been cut down or just as a substitution for a living tree. In this study, which regards creation as simply waiting for an external visitation that only constitutes emptiness, it is instead a tribute to the log's potentiality that it is described as just a log. As also the hypothesis tributes, the Onbashira is seen as embodying de-creation by being just a log.

Abe (Hinako Abe, a Japanese poet, 1953-) gave me some insightful advice about her views on this proposition. Just as Agamben saw the key to de-creation in "Bartleby," we can see the key to Onbashira's de-creation in the story of "Winnie the Pooh." According to Abe, there is a "Winnie the Pooh" story that is about the search for the North Pole $[30,54]$. However, Pooh and his friends see the pole as a "stick" rather than an "axis." The group finally finds a piece of the "pole" and sticks it in the ground, and then call the North Pole. The difference between the Onbashira as an interface and as Kakiwari is precisely this difference between an axis and a stick. The Onbashira is not an axis implying a connection between heterogeneous things but a log implying a distinct break between heterogeneity. The Onbashira is just a log without any pretensions, thoroughly untouched to the outside, giving no meaning to it, but rather something that evaporated the meaning. It is the log as Kakiwari. It is precisely because they build the Onbashira as Kakiwari, in which the outside is externalized, and their latent power of potentiality is demonstrated.

In this context, it is important to discuss an interesting study on the Japanese beliefs about pillars ("Hashira shink $\left.\bar{o}^{\prime}\right)$. In the text of "Nihon Shoki" (The Chronicles of Japan), during the creation of heaven and earth, when the heavens and earth were inseparable and chaotic, "Kizashi" (a kind of bud, or a pillar-like object as a sign or an omen of something) first appeared in the faint black chaos. Then, the heaven/earth and yin/yang were established, and then the kami (Japanese deities) appeared [55]. In many mythologies, such as Christianity, the creator appears first and is responsible for the subsequent creation, whereas in "Nihon Shoki," a kind of pillar-like object, Kizashi, appears first. This pillar serves and stands as the frontier itself. The Onbashira is no different. It is not a boundary that connects to the outside as a simple other side, nor does it represent a pseudo-outside as an alternate world. Rather, it is erected as a frontier itself. It is creation as de-creation, putting a crack of the gap by Kakiwari-izing the world. Because of the representation of the Onbashira as Kakiwari, the Onbashira festival brings us the happiness of invoking the outside. It is said that the festival has never been discontinued, even in times of war.

I depicted this de-creation of the Onbashira as a four-panel folding screen. A folding screen is a tool that divides an interior space. The addition of paintings and other decorations to it has developed the screen into not only a tool but also a form of art. In my landscapes of the four pillars presented in Figure 8, each landscape is unrelated and independent, and they are yet made into a single screen, which differs from the usual folding screen painting style. The title " $Z u-e$ " mentions two styles of landscapes that are shown as a " $\mathrm{Zu}$ " (figure), which describes the state of things, but also are shown as an " $e$ " (painting) that expresses something abstract. The pillar of the shrine forest, pillar of the city, pillar of the ghost (a geyser near Lake Suwa that appears and disappears), and pillar of rocks are the four folding screens that separate the view and show only the function of Kakiwari in front of us. Every viewer, including me, is facing the landscape, but never encounters it. This process of "encountering" entails a series of disconnections and connections. 


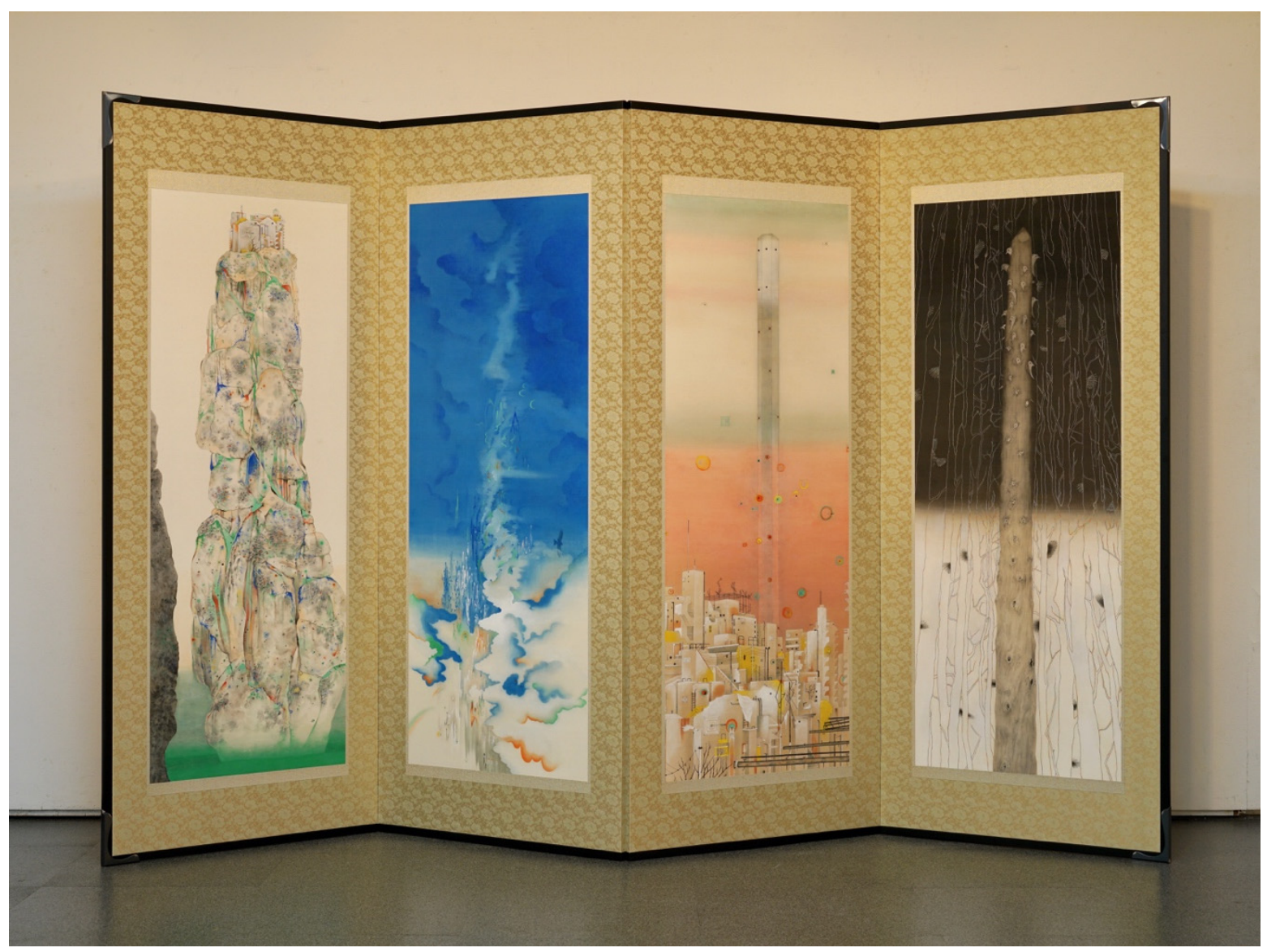

(d) left side; (c) middle left side; (b) middle right side; (a) right side

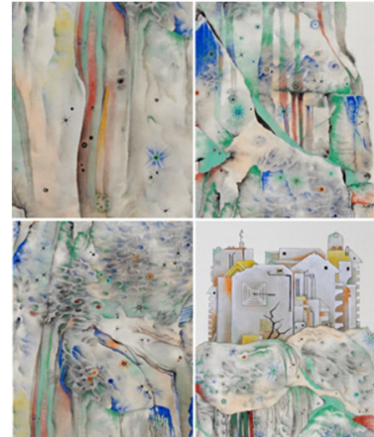

$(\mathbf{d})^{\prime}$

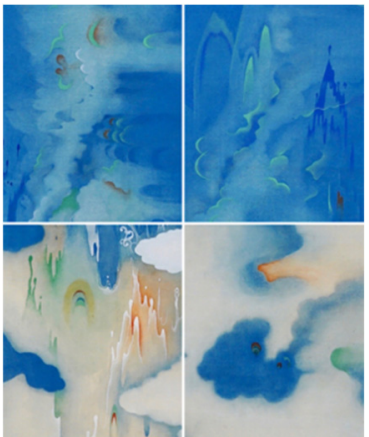

$(\mathbf{c})^{\prime}$

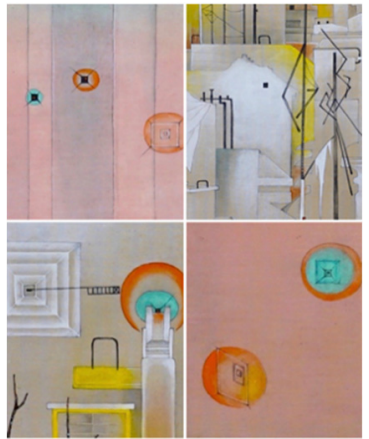

$(\mathbf{b})^{\prime}$

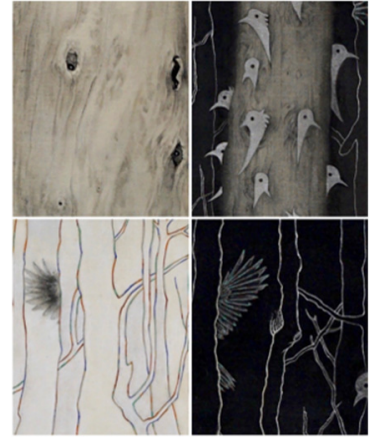

$(\mathbf{a})^{\prime}$

Figure 8. NAKAMURA Kyoko, “Onbashira Zu-e Screen”, four-fold screen, color on silk, $185 \times 306 \mathrm{~cm}$, 2019, paintings each $145 \times 55.5 \mathrm{~cm}$, (a) left side: pillar of the shrine forest, (b) middle left side: pillar of the city, (c) middle right side: pillar of the ghost, and (d) right side: pillar of rocks; (a)'-(d)' Detail of each paintings. Since a fold screen is counted its surfaces from right to left, it is denoted (a)-(d) from the right here. Paintings mounted by Sōgadō, Tokyo, Japan; picture was taken at a gallery Art Space Kimura ASK?, Tokyo, Japan.

\section{Discussion and Conclusions}

Since the art coefficient implies only the gap between intention and realization, it has no positive substance in its own right. De-creation also has no positive substance since it is an image of vacancy between frameworks. Although a thoroughly passive attitude toward the outside cannot be positively expressed, it is very hard to comprehend the active significance of the passive attitude through gaps and emptiness. In this respect, Kakiwari is a substantial flat wall suggesting the outside behind it and is materialized. This materialization has an active nature, in contrast to the thoroughly passive attitude by 
which something can be summoned and waited for. The same is true for a log of Onbashira. Thus, we can positively affirm an active attitude of passivity rather than the gap of the art coefficient or the absence of de-creation. Materializing can be misleading; however, materializing as a thoroughly empty thing means having an active attitude toward the outside. In the past, mathematicians introduced imaginary numbers and zero as entities. The concepts of imaginary numbers and zero helped the field of mathematics develop very much. This same technique can be very effective not only in the arts but also in philosophy and science. If this is the case, the concepts of Kakiwari and Onbashira are important for clarifying the parallelism among philosophy, science and art, which is the development from being to becoming.

In particular, the concepts should have a great impact on the new realism, a type of speculative realism. Speculative realism is a philosophy that recognizes the significance of the outside and is oriented toward the outside of the world. The outside is summoned through a thoroughly passive attitude. The active attitude of philosophy in trying to explain the outside is incompatible with the aspect of the outside, and the moment the outside is explained, the world falls into a stagnant situation. The act of art, with its thoroughly passive attitude, becomes a philosophy that overcomes this problem. In this paper, I have attempted to describe a philosophy that summons the outside while maintaining the passive attitude of art. This is an important attempt that should be extended further attempt, although it can be difficult to make it understandable.

The same assertion can be found in "The Book of Imaginary Beings" by Borges. The book contains a very short sentence, "The Monkey of the Inkpot" [56], which is a part of a collection from a travel book on Southeast Asia written in 1791. The following is an excerpt from Borges which I translated in English from Japanese.

"This animal, which is not rare in the north, is four or five inches long. Its eyes are deep red, and its skin is jet black, smooth as silk and soft as a pillow. A strange instinct is its defining characteristic: it prefers ink. Whenever a person is about to sit down to write, this monkey sits beside him and huddles with his hands together, waiting for him to finish. Then, when he has drunk all the remaining ink, and afterward sits back on its haunches, quiet and satisfied." (Borges cites Wang Tai-Hai, 1791)

There's nothing more to write; I have made a perfectly superb "world" here. However, there is still some ink left in the inkpot. The more I look at this, the more I feel that I have not finished writing. It seems to me that there is something left unwritten. No matter how much I think I have written, I feel that I still have some creativity left in the inkpot. If a monkey reaches out and snatches it from beside me, this monkey being as small as if I could lift it up with five fingers, its fur is smooth and slippery, and it would probably be agile, even if it tried to catch it. The monkey is very unlikely to be caught. There is an emotional attitude that appears to be of deep despair and affirms eternal unfinishedness; however, such a "danger of repetition" [14] is the very attitude of being, and it can be said that it is the "death of art" as pointed out by Kumakura [57]. Those who are inclined toward de-creation always enjoy offering monkeys ink. The monkey drinking the ink means that the monkey constitutes the emptiness (gap) and I achieve de-creation and see completion easily in the most convenient way (read by Nakamura [30].) This is the philosophy of practice that can be found in the work of creative act=de-creation by artists.

Funding: This work was supported by JSPS KAKENHI Grant Numbers 18K18478, 17K18465, and JSPS Topic-Setting Program to Advance Cutting-Edge Humanities and Social Sciences Research Grant Number JPJS00120351748.

Institutional Review Board Statement: Not applicable.

Informed Consent Statement: Not applicable.

Data Availability Statement: This paper contains no data. 
Acknowledgments: I would like to acknowledge all my colleagues, especially my coresearcher, Gunji, who read the manuscript and made suggestions. Gunji's critiques and ideas continue to give me a fundamental image of the outside. This paper is greatly influenced by Gunji's suggestions. I also received a very positive review of this study from reviewers. An unnamed reviewer brought up the idea of "nullspace", which may be a candidate for how AI thinking can genuinely suggest an "outside" without touching it. This suggestion is important; however, since the idea is an enormous topic that exceeds the scope of this paper, I will refrain from discussing it and leave it as a subject for future study.

Conflicts of Interest: The author declares no conflict of interest.

\section{References}

1. Danto, A.C. What Art Is; Sato, T., Translator; Jinbun Shoin: Kyoto, Japan, 2018. (In Japanese)

2. Duchamp, M. Creative Act. Available online: https:/ / shosoin.kunaicho.go.jp/en-US/treasures?id=0000010035\&index=3 (accessed on 17 December 2020).

3. Prigogine, I. From Being to Becoming: Time and Complexity in the Physical Sciences; Koide, S.; Abiko, S., Translators; MISUZU Shobo, Ltd.: Tokyo, Japan, 2019. (In Japanese)

4. Deleuze, G. Différence et Repetition; Zaitsu, O., Translator; Kawade Shobo Shinsha Publishers Inc.: Tokyo, Japan, 1992. (In Japanese)

5. Deleuze, G. Présentation de Sacher-Masoch: Le froid et le Cruel; Hori, C., Translator; Kawade Shobo Shinsha Publishers Inc.: Tokyo, Japan, 2018. (In Japanese)

6. Deleuze, G.; Guattari, F. Qu'est-ce que la Philosophie? Zaitsu, O., Translator; Kawade Shobo Shinsha Publishers Inc.: Tokyo, Japan, 1997. (In Japanese)

7. Derrida, J. Derrida No Ecriture; Nakamura, M., Translator; Meigetsudo Shoten Publishing Inc.: Tokyo, Japan, 2019. (In Japanese)

8. Gabriel, M. Warum es Die Welt Nicht Gibt; Shimizu, K., Translator; Kodansha Ltd.: Tokyo, Japan, 2018. (In Japanese)

9. Gabriel, M. Zentai Shugi No Kokufuku; Nakajima, T., Translator; SHUEISHA Inc.: Tokyo, Japan, 2020. (In Japanese)

10. Meillassoux, Q. Après la Finitude: Essai sur la Nécessité de la Contingence; Chiba, M.; Ohashi, K.; Hoshino, F., Translators; Jinbun Shoin: Kyoto, Japan, 2016. (In Japanese)

11. Harman, G. The Quadruple Object; Okajima, R.; Yamashita, T.; Suzuki, Y.; Ishii, M., Translators; Jinbun Shoin: Kyoto, Japan, 2017. (In Japanese)

12. Gunji, Y.P. Ten-Nen Chinou (Natural-Born Intelligence); Kodansha Ltd.: Tokyo, Japan, 2019. (In Japanese)

13. Gunji, Y.P. Yatte-Kuru (Something Coming); IGAKU-SHOIN Ltd.: Tokyo, Japan, 2020. (In Japanese)

14. Nakamura, K.; Gunji, Y.P. Tankuri: Shooting Creativity; Suiseisha: Tokyo, Japan, 2018. (In Japanese)

15. Agamben, G. Bartleby, o, Della Contingenza; Takakuwa, K., Translator; GETSUYOSHA Limited: Tokyo, Japan, 2005. (In Japanese)

16. Beteru-no-ie. Beteru no ie no Tojisha Kenkyu; IGAKU-SHOIN Ltd.: Tokyo, Japan, 2005. (In Japanese)

17. Seikkula, J.; Arnkil, T.E. Open Dialogues and Anticipations: Respecting Otherness in the Present Moment; Saito, T., Translator; IGAKU-SHOIN Ltd.: Tokyo, Japan, 2019. (In Japanese)

18. Bethel's House. Available online: https:/ / urakawa.bethel-net.jp/ (accessed on 24 October 2020). (In Japanese).

19. Gunji, Y.P. Semiotics of "Co-creation = Cultivation of Expression": Deconstruction and Endo-Existence of Myself. Cocreationology 2019, 1, 5-13. Available online: https://nihon-kyousou.jp/cocreationology/vol1_no1/Cocreationology_1-1-3.pdf (accessed on 1 December 2020). (In Japanese)

20. Gunji, Y.P.; Nakamura, K.; Minoura, M.; Adamatzky, A. Three types of logical structure resulting from the trilemma of free will, determinism and locality. Biosystems 2020, 195. [CrossRef] [PubMed]

21. Gunji, Y.P. Seimei Bidou Dani Sezu (Life Stands Still); SEIDOSHA: Tokyo, Japan, 2018. (In Japanese)

22. Nakamura, K.; Gunji, Y.P. Entanglement of Art Coefficient, or Creativity. Found. Sci. 2020, 25, 247-257. [CrossRef]

23. Los Angeles County Museum of Art. Available online: https://collections.lacma.org/node/239578 (accessed on 28 December 2020).

24. Maturana, H.R.; Varela, F.J. Autopoiesis and Cognition: The Realization of Living; Kawamoto, H., Translator; KOKUBUNSHA LTD.: Tokyo, Japan, 1991. (In Japanese)

25. Varela, F.J. The Principles of Biological Autonomy; North-Holland: New York, NY, USA, 1979.

26. Cultural Heritage Online. Available online: https://bunka.nii.ac.jp/heritages/detail/271463 (accessed on 28 December 2020). (In Japanese)

27. Lautréamont, I.D. Les Chants de Maldoror; Kurita, I., Translator; Gendaishichosha: Tokyo, Japan, 1961. (In Japanese)

28. The International Dada Archive. Available online: http://sdrc.lib.uiowa.edu/dada/blindman/2/04.htm (accessed on 28 December 2020).

29. Nakamura, K.; Gunji, Y.P. Painted Board Girls as the Device towards De-creation. Cocreationology 2020, 2, 1-12. Available online: https://nihon-kyousou.jp/cocreationology/vol2_no1/Cocreationology_2-1-1.pdf (accessed on 1 December 2020). (In Japanese)

30. Nakamura, K. Kakiwari no Mi wo Uguisu, Mugenshō no Kōfuku (The sorrow of body as a painted board "Kakiwari", is the happiness infinitesimal small). In Affectus: Sei no Sotogawa ni Fureru (Touching the Outside of the Life); Nishii, R., Yanai, T., Eds.; Kyoto University Press: Kyoto, Japan, 2020; pp. 8-40. (In Japanese) 
31. Panofsky, E. Die Perspektive als "symbolische Form"; Kida, G.; Kawado, R.; Uemura, K., Translators; TETSUGAKU SHOBO: Tokyo, Japan, 2003. (In Japanese)

32. Takashina, S. Art and Aesthetics in Modern Japan; SEIDOSHA: Tokyo, Japan, 1986. (In Japanese)

33. Mitsui Bunko (Ed.) Pictorial Record of Mitsui Bunko, The Museum of Art as an Annex (Bekkan): Paintings Collected throughout the Whole History of the Mitsui Families; Mitsui Bunko: Tokyo, Japan, 2002; pp. 16-17. (In Japanese)

34. Okuda, A. A characteristic aspect in producing Tagasode screens: The study of designs in the motif of kosodes painted on Tagasode screens. J. Jpn. Soc. Design 2008, 53, 1-15. Available online: https://ir.library.osaka-u.ac.jp/repo/ouka/all/53397/jjsd53_001.pdf (accessed on 1 December 2020). (In Japanese)

35. Anonymous. The Tales of Ise; Abe, T., Translator; Kodansha Ltd.: Tokyo, Japan, 1979; Volume 1, pp. 51-64. (In Japanese)

36. Shizuoka Prefectural Museum of Art. Available online: http://spmoa.shizuoka.shizuoka.jp/japanese/collection/symphony/ fukei/pt1_30.php (accessed on 28 December 2020). (In Japanese)

37. Nara National Museum (Ed.) Yearning for the Pure Land Paradise: The Faith and History of Taimadera Temple: Special Exhibition 1250th Anniversary of the Weaving of the Taima Mandara; Nara National Museum and The Yomiuri Shimbun: Nara, Japan, 2013. (In Japanese)

38. Eikando Zenrin-ji. Available online: http:/ / www.eikando.or.jp/English/zihouichiran_e.html (accessed on 28 December 2020).

39. Orikuchi, S. Shisha No Sho (The Book of the Dead); CHUOKORON-SHA, INC.: Tokyo, Japan, 1974. (In Japanese)

40. Hearn, L. Of the Eternal Feminine. In Nihon No Kokoro; Hirakawa, S., Translator; Kodansha Ltd.: Tokyo, Japan, 1990; pp. 31-63. (In Japanese)

41. Sato, Y. Motto Shiritai Ito Jakuchu; TOKYO BIJUTSU Co., Ltd.: Tokyo, Japan, 2006. (In Japanese)

42. Imperial Household Agency. Available online: https://www.kunaicho.go.jp/culture/sannomaru/syuzou-13.html (accessed on 28 December 2020). (In Japanese)

43. Nihon Keizai Shinbun Inc.; Iwakiri, Y. (Eds.) HOKUSAI.; Nihon Keizai Shinbun, Inc.: Tokyo, Japan, 2005; p. 274. (In Japanese)

44. Imahashi, R. Hokusai's Watermelon as a Symbol of the Star Festival (Kikkoden) and The Romance of the Milky Way. Bull. Fac. Lit. Tokai Univ. 1996, 65, 1-18. (In Japanese)

45. ColBase. Available online: https://colbase.nich.go.jp/collection_items/tnm/A-1398?locale=en (accessed on 28 December 2020).

46. Mori, Y. Hanakuidori Mon-You Tenkai; Rocco Shuppan: Tokyo, Japan, 1974. (In Japanese)

47. Imperial Household Agency. Available online: https:// shosoin.kunaicho.go.jp/en-US/treasures?id=0000010035\&index=3 (accessed on 20 October 2020). (In Japanese)

48. Suwa Taisha. Available online: http:/ / suwataisha.or.jp/ (accessed on 22 January 2021). (In Japanese)

49. Shimo-suwa Choshi Hensan Iinkai (Ed.) Shimo-Suwa ChoShi; Koyo Shobo: Tokyo, Japan, 1963. (In Japanese)

50. Nakazawa, S. Seirei No Ö; Kodansha Ltd.: Tokyo, Japan, 2018. (In Japanese)

51. Gunji, Y.P. Theory of Life (Seimei Riron); Tetsugaku-Shobou Pub. Co.: Tokyo, Japan, 2006. (In Japanese)

52. Gunji, Y.P.; Kamiura, M. Observational heterarchy enhancing active coupling. Phys. D 2004, 198, 74-105. [CrossRef]

53. Gunji, Y.P.; Niizato, T.; Murakami, H.; Tani, I. Typ-Ken (an Amalgam of Type and Token) Drives Infosphere. Knowl. Technol. Policy 2010, 23, 227-251. [CrossRef]

54. Milne, A.A. An expotition to the North Pole. In Kuma No Pu San E-Hon; Ishii, M., Translator; Illustrated by Shepard, E.H.; Iwanami Shoten, Publishers.: Tokyo, Japan, 1982; Volume 6. (In Japanese)

55. Miyake, H. Minzoku shukyō ni okeru hashira no sinkō to girei. Kokugakuin Univ. Front. Res. Proj. Bull. Res. Vis. Doc. Humanit. 2004, 1, 49-63. (In Japanese)

56. Biblioteca Landivariana, Universidad Rafael Landívar. Available online: http://biblio3.url.edu.gt/Libros/borges/imaginarios. pdf (accessed on 9 March 2021).

57. Kumakura, T. Geijutsu 2.0; Shunjusha Publishing Company: Tokyo, Japan, 2019. (In Japanese) 